\title{
Differences in Risk Tolerance and Asset Allocation among White, Black, and Hispanic Households in the United States
}

\author{
Takanori Hisada $^{1}$ \\ ${ }^{1}$ Graduate School of Economics, Osaka University, Toyonaka, Osaka, Japan \\ Correspondence: Takanori Hisada, Graduate School of Economics, Osaka University, Machikaneyama 1-7, \\ Toyonaka, Osaka 560-0043, Japan. E-mail: pge023ht@student.econ.osaka-u.ac.jp
}

Received: November 6, 2017

Accepted: November 28, 2017

Online Published: December 10, 2017

doi:10.5539/ijef.v10n1p93

URL: https://doi.org/10.5539/ijef.v10n1p93

\begin{abstract}
This study examines differences in risk tolerance and asset allocation among white, black, and Hispanic households in the United States. Regressions are run using a sample chosen by propensity score matching because there are substantial differences in the distributions of covariates among race and ethnicity. This study finds that white, black, and Hispanic households are more likely to have similar risk tolerances. In addition, this study finds that all three households are more likely to have similar asset allocations. Simultaneously, in practice, there is wealth inequality between whites and nonwhites. These results imply that differences among race and ethnicity do not affect risk tolerance and asset allocation, and therefore, wealth inequality between whites and nonwhites is not attributed to asset allocation.
\end{abstract}

Keywords: risk tolerance, asset allocation, race, ethnicity, propensity score match

\section{Introduction}

This study examines differences in risk tolerance and asset allocation among race and ethnicity in the United States. The United States is a multiracial nation composed of various races and ethnicities, such as white, black, and Hispanic. However, the nation is predominantly comprised of whites, who represented 72 percent of the population of 308.7 million people in the 2010 census (Hixson et al., 2011). In practice, wealth inequality arises between white and nonwhite. According to the 2010 Survey of Consumer Finances, whites have a rough mean net worth of $\$ 680,000$ relative to $\$ 100,000$ for blacks. As determinants of wealth inequality, Cagetti and Nardi (2008) explain that income, taxation, inheritance, human capital, and portfolio choice affect wealth inequality. As people are more anxious about social security, it is expected to increase opportunities for asset allocation. Moreover, shifting from a defined benefit plan to a defined contribution plan is important for individuals to make asset allocation at their own discretion. Eventually, asset allocation affects future wealth. Thus, it is im- portant to investigate whether differences among race and ethnicity affect risk tolerance and asset allocation and cause wealth inequality.

Several prior studies have analyzed differences in risk tolerance and asset allocation among race and ethnicity. With regard to for risk tolerance, whites are more likely to take risk than are blacks and Hispanics (Sung \& Hanna, 1996). Regarding asset allocation, whites are more likely to hold risky assets than are blacks and Hispanics (Hanna et al., 2010). Furthermore, Keister (2000) suggests that wealth inequality is caused because whites are more likely to have risky assets than are blacks. Hispanics are less likely to take risks and to hold risky assets, such as stock, since wealth inequality arises between them (Coleman, 2003).

Compared with prior studies, the contribution of this study is two-fold. First, this study uses a novel analysis method. Prior studies use mainly simple regression methods, such as logit models, to investigate whether differences of race and ethnicity influence risk tolerance and asset allocation. Variables that influence risk tolerance and asset allocation, such as income and education, are added as covariates and as a result, the prior literature suggests that differences of race and ethnicity influence risk tolerance and asset allocation. However, characteristics differ substantially by race and ethnicity, especially between whites and nonwhites. For example, whites have high average income and education relative to nonwhites. In particular, households who have more than $\$ 100$ million tend to be white. Cochran (1965) and Rubin (2001) suggest that regression analysis cannot reliably control differences in covariates when there are substantial differences in the distribution of covariates in the groups. Prior studies have analyzed the influence of the differences among race and ethnicity with the whole 
sample composed of a high average income and education group and a low average income and education group, and have found that the coefficients of race and ethnicity are statistically significant and that racial differences influence risk tolerance and asset allocation. However, those results may have low reliability. On the contrary, this study conducts analysis using a method that regresses after the sample of similar characteristics among race and ethnicity is chosen by propensity score matching (PSM). If the coefficients of race and ethnicity show statistically significant differences even with a sample of similar characteristics, there is reliability of results that show differences of race and ethnicity influence risk tolerance and asset allocation. In fact, combining regression and matching substantially reduces bias (Rubin, 1973, 1979; Rubin \& Thomas, 2000; Glazerman et al., 2003; Abadie \& Imbens, 2011).

The second contribution of this study is that it investigates not only risky assets but also assets with various levels of risk and whether a particular race or ethnicity is more likely to hold a particular asset. Prior studies mainly have focused on risky assets only, such as stock. In traditional portfolio decisions based on the expected utility model, risk-averse investors invest in risky assets as long as the expected return is higher than the risk-free rate (Arrow, 1971). Haliassos and Bertaut (1995) indicate that stocks show historically higher returns than the risk-free rate and that households in the United States should have held more stocks, but that around 75 percent of households have not held stocks. However, investigating only risky assets does not reveal whether a particular race or ethnicity is more likely to hold a particular asset.

The analysis results are as follows. Differing from the prior studies, the PSM analysis results imply that white, black, and Hispanic households are more likely to have risk tolerance at a similar level, and that differences among race and ethnicity do not affect risk tolerance. Regarding whether to own assets, although the results with PSM indicate that black and Hispanic households are less likely to own almost all assets than are white households, they also indicate that black households are more likely to own some assets, such as US government savings bonds and real estate, at similar levels to white households. At the same time, black and Hispanic households are more likely to own almost all assets at similar levels. In addition, this study finds that a particular race and ethnicity is less likely to own a particular asset. In particular, black households are substantially less likely to own transaction accounts. Hispanic households are less likely to own US government savings bonds. These results suggest that differences in race and ethnicity affect whether to own assets. However, regarding asset allocation, PSM shows that white and black households have similar asset allocation while white and Hispanic households have similar asset allocation except for transaction accounts. Hispanic households have higher asset allocation share in transaction accounts than white households. At the same time, the results indicate that Hispanic and black households have similar asset allocation. These results suggest that white, black, and Hispanic households have similar asset allocation and that differences by race and ethnicity do not necessarily influence asset allocation.

As described above, in practice, there is wealth inequality between whites and nonwhites. Prior studies suggest that the reason that wealth inequality arises between whites and nonwhites is that nonwhite households are less likely to take risk and to hold risky assets than are white households. However, white, black, and Hispanic households take risk at a similar level and have similar asset allocation. Differences among race and ethnicity do not necessarily influence risk tolerance and asset allocation. Therefore, these results imply that wealth inequality between whites and nonwhites is not attributed to asset allocation.

The organization of the rest of this paper is as follows. The next section conducts a literature review of culture and behavior, risk tolerance, and asset allocation. In Section 3, hypotheses are provided. Section 4 describes the data, characteristics among race and ethnicity, and provides the analysis methods of this study. Section 5 reports and interprets the empirical results. Section 6 concludes.

\section{Literature Review}

\subsection{Culture and Behavior}

Ogden et al. (2004) explain that culture influences consumer perceptions and behavior. Moreover, differences in culture between not only a home country and a foreign country but also subcultures of domestic races and ethnicity influence behavior. Valencia (1989) focuses on whites and Hispanics and finds statistically significant differences in consumer behavior between them. This arises from differences not in income and education variables but in cultural values. By contrast, Rokeach and Parker (1970) investigate differences in values between whites and blacks. They indicate that differences in values between whites and blacks disappear or shrink when income and education are controlled. They conclude that behavioral differences are caused by differences in social position rather than race. 


\subsection{Risk Tolerance}

Sung and Hanna (1996) analyze various factors to risk tolerance. As individuals acquire higher education, they are more likely to take risk. White respondents are more likely to take risk than are nonwhite respondents. Income increases expected for investment gain positively affect risk tolerance. Individuals who are 30 years or more away from retirement are more likely to take risk than are other people. Single women are less likely to take risk than are single men or couples. Households comprising five people or more are not less likely to take risk than are other households. Yao et al. (2005) focus on differences in race and ethnicity among white, black, and Hispanic households and investigate differences in risk tolerance. They review prior studies and report that white households are more likely to take risk than are nonwhite households regardless of risk measure. Furthermore, they themselves analyze risk tolerance, and find that white households are more likely to take risk than are black households, and that black households are more likely to take risk than are Hispanic households. However, white households are not more likely to take substantial risk than are nonwhite households. Yao et al. (2011) obtain the same results. Coleman (2003) shows that white households are more likely to take risks than are black and Hispanic households but the coefficient of black households is no longer statistically significant compared to white households when net worth is controlled. By contrast, the coefficient of Hispanic households is still negatively statistically significant compared to white households even when net worth is controlled. She emphasizes the necessity of net worth in an analysis.

\subsection{Risky Assets Choice}

Gutter et al. (1999) define stock and business asset as risky assets. They indicate that black households are less likely to choose risky assets than are white households. They conclude that racial differences in decision making for risky assets may be caused by the number of children and household size. As for black households, on the one hand, the presence of a child increases the likelihood of owning risky assets. On the other hand, the number of households decreases the likelihood of owning risky assets. Wang and Hanna (1997) report that older people are more likely to choose risky assets, white households are more likely to choose risky assets than are black households, and Hispanic households are more likely to choose risky assets than are black households. Zhong and Xiao (1995) show that people with higher education are more likely to hold stocks and bonds, and white households are more likely to hold stocks and bonds than are nonwhite households when income and other variables are controlled. In addition, older people and those with higher income are more likely to hold stocks. Haliassos and Bertaut (1995) indicate that nonwhite households are less likely to choose stocks than are white households, although gender and marital status do not influence the likelihood of owning stock when controlling all other variables. Campbell (2006) indicates that white households are more likely to own private businesses than are nonwhite households and that white households have higher portfolio shares of stocks than do nonwhite households. Gutter and Fontes (2006) use the Heckman two-step estimator and find that black households are less likely to choose risky assets than are white households, but there is little evidence of racial differences in the ratio of net worth invested in risky assets when selection bias is controlled. Hanna et al. (2010) show that black and Hispanic households are less likely to choose risky assets than are white households even when education and other variables are controlled. However, Blinder-Oaxaca decomposition analysis shows that if black households have the average characteristics of white households, then black and white households have the same risky assets level. At the same time, if Hispanic households have the average characteristics of white households, then the difference between Hispanic and white households is much smaller. However, Barsky et al. (2002) indicate that the use of Blinder-Oaxaca decomposition analysis is misleading for the estimation results in regarding the gap between races. Straight (2002) analyzes differences in asset allocation between white and black households. He divides white and black households into low (high) income and education groups and calculates the median of assets. He finds that differences in asset allocation between white and black households are much smaller than the median of assets calculated before white and black households are divided.

\subsection{Wealth Inequality and Asset Allocation}

Wealth inequality between white and black has been reported for a long time (Terrell, 1971). Badu et al. (1999) investigate assets and debts between white and black households. They suggest black households have less net worth than white households in the long run because black households are less likely to take risk and to hold risky assets. Keister (2000) analyzes the relationship between wealth inequality and asset ownership among white and black households. She reports that white households are more likely to hold risky assets than are black households, and therefore, the net wealth of white households is likely to increase faster than that of black households. This causes wealth inequality between them. In the relationship between risk tolerance and investment behavior, Coleman (2003) reports that Hispanic households are less likely to take risks and choose risky assets than are white households, and so, there exists wealth inequalty between them. Choudhury (2001) 
indicates that the net worth of white households is larger than that of black and Hispanic households and a wealth gap arises from differences in asset ownership by race and ethnicity. In particular, nonwhite households are less likely to own risky and high-yield assets than are white households. Altonji and Doraszelski (2005) report that the wealth of whites is accumulated more rapidly than that of blacks and this is caused by differences in savings behavior and rates of return on assets rather than donations and inheritance.

\section{Hypotheses}

Although the United State is a multiracial nation, it is difficult to amalgamate its racial and ethnic original cultures and identities, which appear as racial and ethnic original behavior and characteristics (Yinger, 1985). Kara and Kara (1996) indicate that cultural differences are processed in consumption motivation and choice criterion, which influence consumption behavior. With respect to investment behavior, Yao et al. (2005) report that differences in culture among race and ethnicity affect investment because there are different perceptions that arise from differences in culture among race and ethnicity. Therefore, it can be said that culture is important for preference and influences risk tolerance and asset allocation. In addition, Ogden et al. (2004) indicate that cultural values influence preference according to acculturation level and change in cultural values. Kara and Kara (1996) report that choice behavior differs according to acculturation level. Thus, it can be said that not only differences in culture but also the acculturation level to culture and cultural values influence risk tolerance and asset allocation. As for black people, although most black Americans are of African origin, their degree of acculturation to American culture is high and most have lost African culture. Therefore, black and white people have similar cultural values (Valencia, 1989). From the above, this study proposes the following hypothesis.

Hypothesis 1: Black respondents are more likely to have risk tolerance at a similar level to that of white respondents.

As described earlier in this section, black people have similar cultural values and behavior to white people. Thus, the following hypothesis is proposed.

Hypothesis 2: Black respondents are more likely to hold a similar share of asset allocation in each asset to white respondents.

Turning to Hispanic people, most Hispanic Americans are immigrants who have preserved much of their culture, language, and traditions in the United States. Moreover, Hispanic culture is constantly reinforced by new immigrants from Latin America (Valencia, 1989). In practice, the population of Hispanic Americans in 2010 increased about 43 percent compared with that of 2000 (Ennis et al., 2011). Because their degree of acculturation to American culture is low, cultural values differ between Hispanics and whites (Valencia, 1989). Therefore, Hispanic people do not have similar levels of risk tolerance to white people. In addition, Hispanic Americans, especially men, have strongly masculine orientation and behavior (Casas et al., 1994). In other words, risk- averse behavior, that is, low risk tolerance behavior, signals weakness to individuals (Yao et al., 2005). Thus, this study proposes the following hypothesis.

Hypothesis 3: Hispanic respondents are more likely to have higher risk tolerance than are white respondents.

As described earlier in this section, Hispanic culture values and behavior differ to white cultural values and behavior. At the same time, Hispanic people are oriented towards the present, which they regard as more important than the future (Okun et al., 1998). In other words, Hispanic people have high time preference. For these reasons, this study proposes the following hypothesis.

Hypothesis 4: Hispanic respondents are more likely to hold lower shares of asset allocation in each asset than are white respondents.
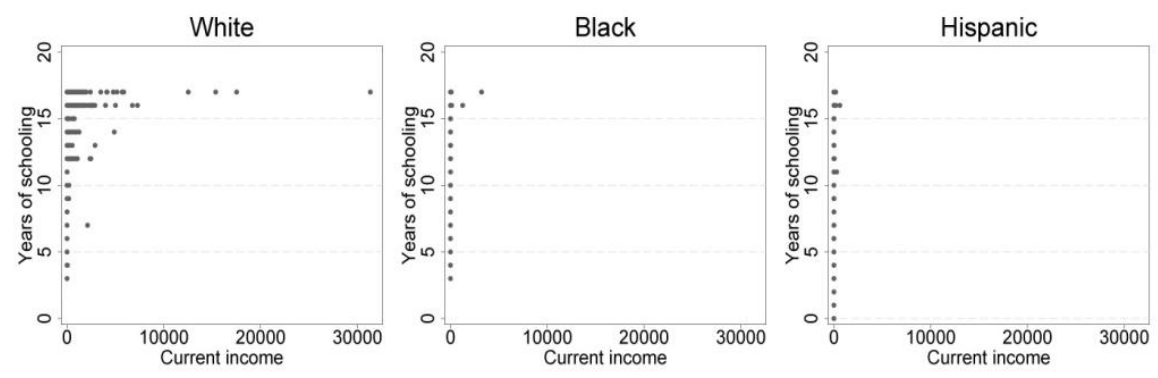

Notes: First imputation set is used, and the unit is $\$ 10,000$

Figure 1. Scatter plot of current income and years of schooling 


\section{Data and Methods}

\subsection{Data}

This study uses datasets of the 2010 Survey of Consumer Finances (SCF). The SCF has been conducted every 3 years by the Federal Reserve Board in cooperation with the Internal Revenue Service since 1983. The SCF is intended to provide various information of financial characteristics of households in the United States. Detailed data collected include assets, such as transaction account, stock, and liabilities, such as credit cards and loans. Other information has been collected on employment, inheritance and so on. As another feature, the SCF is composed of both an area-probability sample and a special sample derived from tax data. Thus, the SCF oversamples households with unusual characteristics, such as high-income households (Kennickell et al., 1996). The SCF asks respondent to choose seven race or ethnic categories that they feel best describes them. In the public datasets, seven categories are integrated into four categories of white, black, Hispanic, and other. This study chooses whites blacks, and Hispanics as the analysis targets.

The SCF has publicly provided five complete datasets with replicated datasets and processed missing data since 1992 instead of a survey dataset. The multiple imputation method suggested by Rubin (1987) is used in processing technology of incomplete data. The multiple imputation method uses stochastic multivariate methods to replace each missing value with two or more values obtained to simulate the sampling distribution of the missing values (Montalto \& Sung, 1996). Regression analysis needs to be considered using multiple imputation. In addition to multiple imputations, the descriptive statistics need to take account of nonresponse-adjusted sampling weights and replication weights.

\subsection{Characteristics among Race and Ethnicity}

As described in Section 1, characteristics differ among race and ethnicity. Prior studies mainly use regression analysis and control characteristics, such as income and education, in order to investigate whether racial and ethnic differences influence risk tolerance and asset allocation. Prior studies indicate that differences among race and ethnicity in- fluence risk tolerance and asset allocation.

Figure 1 shows a scatter plot of current income and years of schooling by white, black, and Hispanic respondents. Some Hispanic respondents have lower education and income than some whites. At the same time, some white respondents have much higher income than do some Hispanic respondents. Income and education level are an example of characteristics among race and ethnicity. There are racial and ethnic differences in various characteristics, such as age and employment status. Table 1 shows the unweighted descriptive statistics (Note 1). For example, there are 14.22 mean years of schooling of white respondents in a 95 percent confidence interval range from 14.15 to 14.29. Meanwhile, there are 11.48 mean years of schooling of Hispanic respondents in a 95 percent confidence interval range from 11.18 to 11.78 . This indicates that the lower bound of the confidence interval of white respondents does not cover the upper bound of confidence interval of Hispanic respondents. The white group has relatively higher average education and the Hispanic group has relatively lower average education. As for whites and blacks, the mean age of the white group is 52.69 years in a 95 percent confidence interval range from 52.24 to 53.15 . At the same time, the mean age of the black group is 46.65 years in 95 percent confidence interval range from 45.60 to 47.69 . This shows that the lower bound of the confidence interval of the white group does not overlap the upper bound of the confidence interval of the black group. The white group is relatively older than the black group. In addition, the lower bound of the confidence interval of the white group does not overlap the upper bound of the confidence interval of the black or Hispanic group in income, net worth, employment status, and health status.

Cochran (1965) and Rubin (2001) report that regression analysis cannot reliably control differences in covariates when there are substantial differences in the distribution of these covariates in the groups. However, prior studies performed simple regression by using the entire sample without considering substantial differences in the distribution of covariates among race and ethnicity. This study improves prior study methods.

\subsection{Sample Construction}

This study uses two methods. Method A is the same method as prior studies and Method B is an improvement on the previous method. The results of Method A are compared with those of Method B.

Method A performs regression by using the whole sample. The sample size of Method A is 6,188 people and is composed of 4,759 white people, 790 black people, and 639 Hispanic people. Meanwhile, Method B analyzes by the method of regressing after the sample of similar characteristics is chosen by matching instead of merely regressing using the whole sample. In practice, combining regression and matching substantially reduce bias (Rubin, 1973, 1979; Rubin \& Thomas, 2000; Glazerman et al., 2003; Abadie \& Imbens, 2011). The results of 
Method B have higher reliability than those of Method A. This study uses PSM proposed by Rosenbaum and Rubin (1983). The propensity score, $e\left(\mathbf{x}_{i}\right)$, is defined as the conditional probability that the $i$-th unit is assigned to a particular treatment given the covariates, $\mathbf{x}_{i}$.

$$
e\left(\boldsymbol{x}_{i}\right)=\operatorname{pr}\left(z_{i}=1 \mid \boldsymbol{x}_{i}\right)
$$

where $z_{i}$ is the indicator that denotes whether $z_{i}=1$ or $z_{i}=0$ according to whether unit $i$ is assigned to the treatment or the control, respectively.

Table 1. Descriptive statistics of unweighted characteristics

\begin{tabular}{|c|c|c|c|c|c|c|c|c|c|}
\hline \multirow[b]{3}{*}{ Male } & \multicolumn{3}{|c|}{ White } & \multicolumn{3}{|c|}{ Black } & \multicolumn{3}{|c|}{ Hispanic } \\
\hline & \multirow{2}{*}{$\begin{array}{c}\text { Mean } \\
0.805\end{array}$} & \multicolumn{2}{|c|}{ 95\% Conf Interval } & \multirow{2}{*}{$\frac{\text { Mean }}{0.572^{* * *}}$} & \multicolumn{2}{|c|}{ 95\% Conf Interval } & \multirow{2}{*}{$\frac{\text { Mean }}{0.735^{* * *, 3}}$} & \multicolumn{2}{|c|}{ 95\% Conf Interval } \\
\hline & & 0.793 & 0.816 & & 0.537 & 0.607 & & 0.701 & 0.770 \\
\hline Age & 52.693 & 52.241 & 53.145 & $46.645^{* * *}$ & 45.597 & 47.693 & $42.081^{* *, 3}$ & 41.078 & 43.084 \\
\hline Years of schooling & 14.217 & 14.149 & 14.286 & $13.011^{* * *}$ & 12.846 & 13.177 & $11.479^{* *, 3}$ & 11.181 & 11.776 \\
\hline Married & 0.683 & 0.670 & 0.697 & $0.450^{* * *}$ & 0.416 & 0.485 & $0.671^{3}$ & 0.635 & 0.708 \\
\hline Family size & 2.463 & 2.423 & 2.503 & $2.344^{* *}$ & 2.241 & 2.446 & $3.118^{* * *, 3}$ & 2.992 & 3.245 \\
\hline The number of children & 1.465 & 1.417 & 1.513 & 1.531 & 1.395 & 1.667 & $1.215^{* * *, 3}$ & 1.078 & 1.352 \\
\hline The proportion of children & 0.573 & 0.559 & 0.587 & 0.570 & 0.535 & 0.604 & $0.475^{* * * 3}$ & 0.436 & 0.513 \\
\hline Not working & 0.275 & 0.262 & 0.287 & $0.338^{* * *}$ & 0.305 & 0.371 & $0.177^{* * *, 3}$ & 0.147 & 0.207 \\
\hline \multicolumn{10}{|l|}{ Risk tolerance } \\
\hline No financial risks & 0.359 & 0.345 & 0.372 & $0.565^{* * *}$ & 0.531 & 0.600 & $0.639^{* * * 3}, 3$ & 0.601 & 0.676 \\
\hline Average financial risks & 0.413 & 0.399 & 0.427 & $0.293^{* * *}$ & 0.261 & 0.325 & $0.228^{* * *, 3}$ & 0.196 & 0.261 \\
\hline Above average financial risks & 0.182 & 0.171 & 0.193 & $0.098^{* * *}$ & 0.078 & 0.119 & $0.083^{* * *}$ & 0.062 & 0.104 \\
\hline Substantial financial risks & 0.046 & 0.040 & 0.052 & 0.043 & 0.029 & 0.057 & 0.050 & 0.033 & 0.067 \\
\hline \multicolumn{10}{|l|}{ US economy over the next 5 years } \\
\hline Worse & 0.211 & 0.199 & 0.222 & $0.098^{* * *}$ & 0.077 & 0.118 & $0.135^{* * *, 2}$ & 0.108 & 0.162 \\
\hline About the same & 0.302 & 0.289 & 0.315 & $0.216^{* * *}$ & 0.187 & 0.245 & $0.275^{2}$ & 0.240 & 0.310 \\
\hline Better & 0.487 & 0.473 & 0.501 & $0.686^{* * *}$ & 0.654 & 0.719 & $0.590^{* * *, 3}$ & 0.551 & 0.628 \\
\hline \multicolumn{10}{|l|}{ Health status } \\
\hline Poor & 0.051 & 0.045 & 0.057 & 0.066 & 0.048 & 0.083 & 0.049 & 0.033 & 0.066 \\
\hline Fair & 0.155 & 0.144 & 0.165 & $0.261^{* * *}$ & 0.230 & 0.292 & $0.206^{* * *, 2}$ & 0.175 & 0.238 \\
\hline Good & 0.478 & 0.464 & 0.493 & $0.434^{* *}$ & 0.399 & 0.468 & $0.494^{2}$ & 0.455 & 0.533 \\
\hline Excellent & 0.316 & 0.303 & 0.329 & $0.239^{* * *}$ & 0.210 & 0.269 & $0.251^{* * *}$ & 0.217 & 0.285 \\
\hline Current income(\$) & 770,739 & 574,582 & 966,897 & $101,113^{* * *}$ & 15,120 & 187,106 & $67,413^{* * *}$ & 44,327 & 90,500 \\
\hline Log current income & 11.182 & 11.121 & 11.242 & $10.290^{* * *}$ & 10.217 & 10.364 & $10.379^{* * *}$ & 10.283 & 10.474 \\
\hline Usual income (\$) & 775,675 & 591,951 & 959,400 & $105,012^{* * *}$ & 19,030 & 190,995 & $77,754^{* * *}$ & 52,455 & 103,053 \\
\hline Log usual income & 11.472 & 11.426 & 11.518 & $10.422^{* * *}$ & 10.354 & 10.489 & $10.590^{* * *, 3}$ & 10.523 & 10.656 \\
\hline Net worth $(\$)$ & $10,373,957$ & $8,851,860$ & 11.896 .054 & $742,391 * * *$ & -184.045 & 1.668 .827 & $410,339^{* * *}$ & 75,274 & 745,404 \\
\hline Log net worth & 16.126 & 16.106 & 16.146 & $15.846^{* * *}$ & 15.833 & 15.859 & $15.848^{* * *}$ & 15.836 & 15.860 \\
\hline$N$ & & 4,759 & & & 790 & & & 639 & \\
\hline
\end{tabular}

The treatment group comprises, for example, individuals who participate in training programs (Dehejia \& Wahba, 1999), black individuals (Barsky et al., 2002), or African American mothers (Hill \& Reiter, 2006). This study chooses the Hispanic group, which has the smallest sample size in the dataset, as the treatment group; thus, white and black groups have larger sample sizes than the Hispanic group as the control group. At the same time, the matching method is one-to-one nearest neighbor matching with calipers and replacement. The caliper allows the choice of only pairs of specified distance (value) or less and guarantees common support (Note 2). Rosenbaum and Rubin (1985) suggest that a quarter of standard deviation of propensity score is chosen as the caliper size. The caliper size of Method B is calculated as 0.032. Matching with replacement allows the controls to be used once or more. Compared to matching without replacement, matching with replacement reduces bias (Dehejia \& Wahba, 2002; Smith \& Todd, 2005). A sample that is not chosen as a pair is excluded and the sample size decreases. Eventually, the sample size in Method B is 1,391 people and is composed of 450 white people, 334 black people, and 607 Hispanic people.

Figure 2 shows a histogram of estimated propensity score before and after matching (Note 3 ). The propensity score of the white group before matching is concentrated from 0 to 0.1 and hardly appears at 0.4 or more. At the same time, the propensity score of the black group before matching is concentrated from 0 to 0.1 but not as much as the white group and scarcely appears at 0.5 or more. This suggests that the distributions of the propensity score substantially differ among the white, black, and Hispanic groups. After matching, the distributions of the propensity score become similar among white, black, and Hispanic groups. 

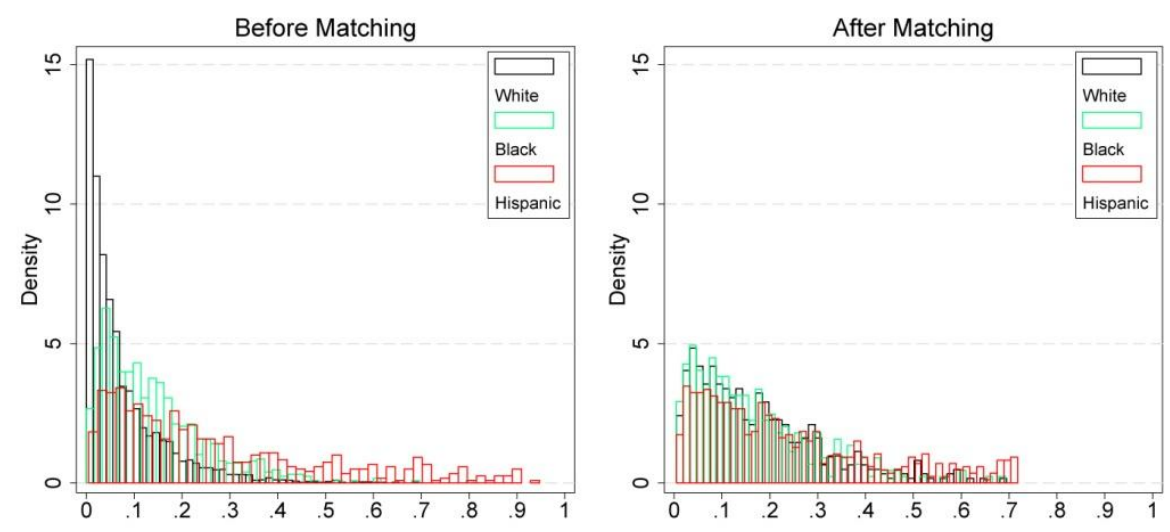

Notes: First imputation set is used

Figure 2. Histogram of estimated propensity score

\subsection{Risk Tolerance}

The SCF includes a multiple-choice question about risk tolerance as follows.

"Which of the following statements on this page comes closest to describing the amount of financial risk that you (and your husband/wife/partner) are willing to take when you save or make investments?"

1) "Take substantial financial risks expecting to earn substantial returns"

2) "Take above average financial risks expecting to earn above average returns"

3) "Take average financial risks expecting to earn average returns"

4) "Not willing to take any financial risks"

This study uses an ordered logit model to analyze differences in risk tolerance by race and ethnicity because risk tolerance is the ordinal variable (Note 4 ).

$$
y_{i}=\alpha_{0}+\alpha_{1} \text { racelethnicity }{ }_{i}+x_{i}^{\prime} \alpha+u_{i}
$$

where $y_{i}$ denotes risk tolerance from 1 to 4 and racelethnicity $y_{i}$ is a dummy variable that denotes individual $i$ 's race or ethnicity. $\mathrm{x}_{i}$ and $u_{i}$ denote covariates and error terms.

\subsection{Asset Allocation}

Prior studies mainly analyze risky assets. Investigating only risky assets does not reveal whether a particular asset tended to be held among a particular race or ethnicity. The various risk-class assets allow us to establish whether a particular race or ethnicity is more (or less) likely to hold a particular asset. This study defines total assets as the following three risk classes: stock, business equity, and real estate chosen as high-risk and high-return assets, mutual funds are chosen as medium-risk and medium-return assets, and US government savings bonds and transaction accounts are chosen as low- risk and low-return assets.

This study uses the two-step estimator suggested by Heckman (1979) since asset allocation analysis consists of two steps (Note 5). The first step is that individuals decide whether to own an asset (e.g., stock).

$$
y_{1 i}=\beta_{0}+\beta_{1} \text { racelethnicity }_{i}+x_{1 i}^{\prime} \beta+u_{1 i}
$$

where $y_{1 i}$ denotes choice of an asset and racelethnicity is a dummy variable that denotes individual $i$ 's race or ethnicity. $\mathrm{x}_{1 i}$ and $u_{1 i}$ denote covariates and error terms. In the second step, if individuals decide to own an asset, $y_{i 1}=1$, and they decide a proportion of an asset to the total assets.

$$
y_{2 i}=\gamma_{0}+\gamma_{1} \text { racelethnicity }_{i}+x_{2 i}^{\prime} \gamma+u_{2 i}
$$

where $y_{2 i}$ donates the proportion of an asset to total assets. $\mathrm{x}_{2 i}$ and $u_{2 i}$ indicates the covariates and error terms. Note that $\mathrm{x}_{2 i}$ are included in $\mathrm{x}_{1 i}$ due to the exclusion restriction. This study assumes that $\left(u_{1 i}, u_{2 i}\right)$ are normal distribution with mean $(0,0)$, variance $\left(\sigma_{1}^{2}, 1\right)$, and covariance $\left(\rho \sigma_{1}, \rho \sigma_{1}\right)$.

\section{Estimation Results}

\subsection{Risk Tolerance}

Table 2 reports the proportions of risk tolerance among white, black, and Hispanic groups. For "not willing to 
take any financial risks," $43.3 \%$ of white, $56.8 \%$ of black, and $65.0 \%$ of Hispanic respondents chose this response. These results show a statistically significant difference among them, which suggests that black and Hispanic respondents are more likely to have low risk tolerance than are white respondents, and Hispanic respondents are more likely to have low risk tolerance than are black respondents. However, the results do not control covariates, such as income.

Table 2. Proportions of risk tolerance

\begin{tabular}{lcccc}
\hline & White & Black & Hispanic & All \\
\hline Take substantial financial risks expecting to earn substantial returns & 0.032 & 0.039 & $0.042^{* *}$ & 0.034 \\
Take above average financial risks expecting to earn above average returns & 0.145 & $0.098^{* * *}$ & $0.080^{* * *}, 1$ & 0.131 \\
Take average financial risks expecting to earn average returns & 0.389 & $0.294^{* * *}$ & $0.229^{* * * * 3}$ & 0.357 \\
Not willing to take any financial risks & 0.433 & $0.568^{* * *}$ & $0.650^{* * *, 3}$ & 0.477 \\
N & 4,759 & 790 & 639 & 6,188 \\
\hline
\end{tabular}

Note. Multiple imputation, sampling and replication weights are used.

${ }^{*} p<0.1,{ }^{* *} p<0.05,{ }^{* * *} p<0.01$ when compared with white.

${ }^{1} p<0.1,{ }^{2} p<0.05,{ }^{3} p<0.01$ when compared with black.

Table 3 shows the estimation results of an ordered logit model. Method A shows that the coeffcients of the black and Hispanic groups are significantly negative. This implies that black and Hispanic respondents are more likely to have low risk tolerance than are white respondents. In addition, this study investigates the relationship between black and Hispanic groups by changing the reference from the white group to the black group (not reported in the tables to save space). The coeffcient of the Hispanic group is significantly negative. This suggests that Hispanic respondents are more likely to have low risk tolerance than are black respondents. These results are consistent with Yao et al. (2005). By contrast, Method B shows that the coeffcients of the black and Hispanic groups are no longer significant. When the reference is changed from the white group to the black group, the coeffcient of the Hispanic group is no longer significant (not reported in the tables). This implies that white, black, and Hispanic respondents are more likely to have risk tolerance at the same level and that differences among white, black, and Hispanic respondents do not influence risk tolerance. Although these results are not consistent with prior studies, recall that the estimate results of Method B have higher reliability. Therefore, the results of Method B support Hypothesis 1, that black respondents are more likely to have risk tolerance at a similar level to white respondents. Meanwhile, the results of Method B reject Hypothesis 3, that Hispanic respondents are more likely to have higher risk tolerance than are white respondents.

Table 3. Estimation results of risk torelance

\begin{tabular}{lcc}
\hline & Method A & Method B \\
\hline Race/Ethnicity: ref $=$ white & & \\
Black & $-0.362^{* * *}$ & -0.068 \\
& $(-4.34)$ & $(-0.25)$ \\
Hispanic & $-0.576^{* * *}$ & -0.121 \\
& $(-5.96)$ & $(-0.52)$ \\
$N$ & 6,188 & 1,391 \\
\hline
\end{tabular}

Note. $t$ statistics in parentheses.

${ }^{*} p<0.1,{ }^{* *} p<0.05,{ }^{* * *} p<0.01$

\subsection{Asset Allocation}

Tables 4 shows the estimation results of the first step. This study focuses on assets that have different results in Methods A and B. The result of stock in Method A shows that the coefficients of the black and Hispanic groups are negatively statistically significant. When the reference is changed from the white group to the black group, the coefficient of the Hispanic group shows no statistically significant difference (not reported in the tables). This implies that black and Hispanic households are less likely to own stocks than are white households and that Hispanic and black households more likely to own stocks at the same level. These results are consistent with prior studies. By contrast, Method B shows that the coefficient of the black group is no longer a statistically significant difference. This result is not consistent with Method A. The coefficient of the Hispanic group is still negatively statistically significant. When the reference is changed to the black group, the coefficient of the 
Hispanic group is not statistically significantly different (not reported in the tables). This suggests that black and white households are more likely to own stocks at the same level and that Hispanic households are less likely to own stocks than are white households.

Turning to real estate in Method A, the coefficient of the black group is not a statistically significant difference. The coefficient of the Hispanic group is negatively statistically significant. When the reference is changed to the black group, the coefficient of the Hispanic group is negatively statistically significant (not reported in the tables) This suggests that white and black households are more likely to own real estate at the same level and that Hispanic households are less likely to own real estate than are white and black households. Meanwhile, in Method $\mathrm{B}$, the coefficients of the black and Hispanic groups are not statistically significant differences. Moreover, when the reference is changed to the black group, the coefficient of the Hispanic group is not a statistically significant difference (not reported in the tables). This implies that white, black, and Hispanic households are more likely to own real estate at the same level.

Table 4. Estimation results of asset allocation: first step

\begin{tabular}{|c|c|c|c|c|}
\hline & Method A & Method B & Method A & Method B \\
\hline & Stock & & Business Equity & \\
\hline \multicolumn{5}{|c|}{ Race/Ethnicity: $r e f=$ white } \\
\hline \multirow[t]{2}{*}{ Black } & $-0.359^{* * *}$ & -0.316 & $-0.375^{* * *}$ & $-0.422^{*}$ \\
\hline & $(-4.21)$ & $(-1.52)$ & $(-4.48)$ & $(-1.87)$ \\
\hline \multirow[t]{3}{*}{ Hispanic } & $-0.487^{* * *}$ & $-0.549^{* * *}$ & $-0.381^{* * *}$ & $-0.349^{* * *}$ \\
\hline & $(-4.46)$ & $(-3.301)$ & $(-4.38)$ & $(-2.79)$ \\
\hline & Real Estate & & Mutual Fund & \\
\hline \multicolumn{5}{|c|}{ Race/Ethnicity: ref $=$ white } \\
\hline \multirow[t]{2}{*}{ Black } & -0.017 & 0.077 & $-0.735^{* * *}$ & $-0.798^{*}$ \\
\hline & $(-0.25)$ & $(0.38)$ & $(-5.34)$ & $(-1.70)$ \\
\hline \multirow[t]{3}{*}{ Hispanic } & $-0.19^{5_{* *}}$ & -0.099 & $-0.480^{* * *}$ & $-0.565^{* *}$ \\
\hline & $(-2.30)$ & $(-0.72)$ & $(-3.36)$ & $(-2.44)$ \\
\hline & US Bond & & Transaction Account & \\
\hline \multicolumn{5}{|c|}{ Race/Ethnicity: ref $=$ white } \\
\hline \multirow[t]{2}{*}{ Black } & $-0.188^{* *}$ & -0.221 & $-0.624^{* * *}$ & $-0.655^{* * *}$ \\
\hline & $(-2.45)$ & $(-1.33)$ & $(-8.20)$ & $(-4.07)$ \\
\hline \multirow[t]{2}{*}{ Hispanic } & $-0.696^{* * *}$ & $-0.674^{* * *}$ & $-0.308^{* * *}$ & $-0.312^{* *}$ \\
\hline & $(-6.20)$ & $(-4.71)$ & $(-3.47)$ & $(-2.14)$ \\
\hline $\mathrm{N}$ & 6,188 & 1,391 & 6,188 & 1,391 \\
\hline
\end{tabular}

Note. $\mathrm{t}$ statistics in parentheses.

${ }^{*} \mathrm{p}<0.1,{ }^{* *} \mathrm{p}<0.05,{ }^{* * *} \mathrm{p}<0.01$.

Choudhury (2001) reports that nonwhites are less likely to own particularly risky and high-yield assets. Moreover, Keister (2000) suggests that inequality between white and black households is caused so that black households are less likely to own risky assets, such as stocks. At least, this study shows that white and black households are more likely to own stocks at the same level and that white, black, and Hispanic households are more likely to own real estate at the same level. Prior studies may not be able to control differences in covariates reliably in order to regress using the whole sample.

Turning to US government saving bonds (US bonds), in Method A, the coefficients of the black and Hispanic groups are negatively statistically significant. When the reference is changed to the black group, the coefficient of the Hispanic group is negatively statistically significant (not reported in the tables). These results suggest that black and Hispanic households are less likely to own US bonds than are white households and that Hispanic households are less likely to own US bonds than are black households. In Method B, the coefficient of the black group is no longer a statistically significant difference. This result is not consistent with Method A. The coefficient of the Hispanic group is still negatively statistically significant. When the reference is changed to the black group, the coefficient of the Hispanic group is negatively statistically significant (not reported in the tables). These results imply that white and black households are more likely to own US bonds at the same level and that Hispanic households are less likely to own US bonds than are black households.

Overall, Method B shows that black households are more likely to own high-risk high-return assets and low-risk low-return assets at the same level as white households. More precisely, black households are more likely to own 
three out of the six assets at the same level as white households. On the other hand, overall, Method B indicates that Hispanic households are less likely to own three risk classes. Hispanic households are less likely than white households to own five out of the six assets. At the same time, Hispanic households are more likely to own assets at the same level as black households except for US bonds and transaction accounts. This implies that differences in race and ethnicity affect whether to own assets.

In addition, this study investigates whether a particular asset is more likely to be owned by a particular race or ethnicity. Figure 3 reports race and ethnicity effects by average marginal effects of each asset in Method B. Transaction accounts are notably less chosen by black households: there are much less likelihood of owning transaction accounts by black households than the other assets. For Hispanic households, US bonds are a notably less chosen asset: Hispanic households are less likelihood of owing US bonds than the other assets. Transaction accounts and US bonds are low-risk low- return assets but there are different results for black and Hispanic households. These tendencies cannot be revealed by only stocks. Only when assets with various risks are investigated will a particular race and ethnicity be revealed as more likely to own a particular asset.

Tables 5 indicates the estimation results of the second step. Following the first step, this study considers stocks, real estate, and US bonds. The stock results in Method A show that the coefficients of black and Hispanic groups are not statistically significant differences. When the reference is changed from the white group to the black group, the coefficient of the Hispanic group is not a statistically significant difference (not reported in the tables). This suggests that white, black, and Hispanic households have the same asset allocation shares in stocks. The results of Method B show the same results as Method A. In other words, white, black, and Hispanic households have the same asset allocation shares in stocks. This result is consistent with white and black households having similar asset allocation shares in risky assets, such as stocks and business equity (Gutter \& Fontes, 2006).

Turning to real estate, in Method A, the coefficient of the black group is positively statistically significant. The coefficient of the Hispanic group is not a statistically significant difference. When the reference is changed to the black group, the coefficient of the Hispanic group is not a statistically significant difference (not reported in the tables). This implies that black households have a higher asset allocation share in real estate than white households and that Hispanic households have the same asset allocation share as do black and white households, that is, Hispanic households have a share between those of black and white households. In Method B, the coefficients of the black and Hispanic groups are not statistically significant differences. This result is inconsistent with Method A. When the reference is changed to the black group, the coefficient of the Hispanic group is not a statistically significant difference (not reported in the tables). This suggests that white, black, and Hispanic households have the same asset allocation shares in real estate.

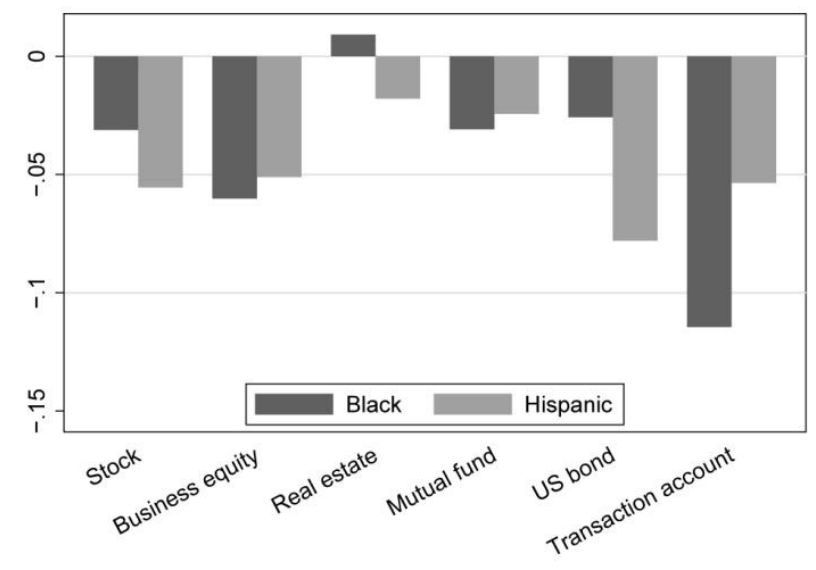

Figure 3. Race and ethnicity effects 
Table 5. Estimation results of asset allocation: second step

\begin{tabular}{lllll}
\hline & Method A & Method B & Method A & Method B \\
\hline Race/Ethnicity: $r e f=$ white & Stock & & Business Equity & \\
Black & & & & \\
& -0.020 & 0.019 & 0.038 & 0.040 \\
Hispanic & $(-0.44)$ & $(0.12)$ & $(0.74)$ & $(0.37)$ \\
& -0.062 & -0.053 & 0.011 & 0.010 \\
& $(-1.03)$ & $(-0.27)$ & $(0.22)$ & $(0.13)$ \\
\hline Race/Ethnicity: ref $=$ white & Real Estate & & Mutual Fund & \\
Black & & & & -0.084 \\
& $0.091^{* * *}$ & 0.081 & $-0.169^{*}$ & $(-0.35)$ \\
Hispanic & $(2.84)$ & $(0.84)$ & $(-1.95)$ & 0.004 \\
& 0.035 & 0.077 & -0.105 & $(0.03)$ \\
\hline & $(0.85)$ & $(1.14)$ & $(-1.30)$ & \\
\hline Race/Ethnicity: ref $=$ white & $\mathrm{US} \mathrm{Bond}$ & & Transaction Account & \\
Black & & & & 0.055 \\
& $0.068 *$ & 0.038 & $0.047^{* * *}$ & $(1.30)$ \\
Hispanic & $(1.68)$ & $(0.26)$ & $(2.63)$ & $0.090^{* * *}$ \\
$\mathrm{~N}$ & 0.159 & -0.061 & $0.073^{* * *}$ & $(3.53)$ \\
\hline
\end{tabular}

Note. $\mathrm{t}$ statistics in parentheses.

${ }^{*} \mathrm{p}<0.1,{ }^{* *} \mathrm{p}<0.05,{ }^{* * *} \mathrm{p}<0.01$.

Now, turning to US bonds, in Method A, the coefficient of the black group is positively statistically significant. The coefficient of the Hispanic group is not a statistically significant difference. When the reference is changed to the black group, the coefficient of the Hispanic group is not a statistically significant difference (not reported in the tables). This suggests that black households have a higher asset allocation share in US bonds than do white households, and Hispanic households have the same allocation share as black and white households, that is, Hispanic households have a share between black and white households. In Method B, the coefficients of the black and Hispanic households are not statistically significant differences. This result is inconsistent with Method A. When the reference is changed to the black group, the coefficient of the Hispanic group is not statistically significantly different (not reported in the tables). This suggests that white, black, and Hispanic households have the same asset allocation shares in US bonds.

In summary, Method A shows that black households have higher asset allocation shares in transaction accounts and US bonds, which are low-risk low-return assets, and real estate, which is a high-risk high return asset. In addition, black households have lower asset allocation shares in mutual funds, which are medium-risk medium-return assets. However, Method B indicates that black and white households have similar asset allocation shares in high-risk high-return assets, medium-risk medium-return assets and low-risk low-return assets. In other words, black households do not have higher or lower asset allocation shares in a particular asset class and have the same asset allocation share in all asset classes as white households. Recall that Method B has higher reliability than Method A. Method A may not be able to control differences in covariates reliably in order to regress using the whole sample. Therefore, Hypothesis 2, that black households are more likely to hold similar asset allocation shares in each asset compared to white households, is supported. By contrast, both Methods A and B show that Hispanic and white households have the same asset allocation shares in high-risk high- return assets, medium-risk medium-return assets, and low-risk low-return assets. In detail, Hispanic and white households have the same allocation shares in all assets except for transaction accounts. There is a higher portfolio share in transaction accounts of Hispanic households compared to white households. Hence, Hypothesis 4, that Hispanic households are more likely to hold lower asset allocation shares in each asset than white households, is rejected. In addition, black and Hispanic households have the same portfolio shares in all assets. These results imply that white, black, and Hispanic households have similar asset allocation and that differences by race and ethnicity do not necessarily influence asset allocation.

\subsection{Robustness Check}

As a robustness check, Method $\mathrm{C}$ conducts two-to-one nearest neighbor matching with calipers and replacement. 
This matching method is to choose the nearest two controls to one treatment, which analyzes with a larger sample size than Method B. Method C has 1,928 people and is composed of 805 white people, 516 black people, and 607 Hispanic people. Overall, the estimate results are similar to those using the one-to-one matching method.

Table 6 shows the estimation results of risk tolerance. These results are similar to Table 3 and suggest that white, black, and Hispanic respondents are more likely to take risk at the same level and that racial and ethnic differences do not affect risk tolerance. Table 7 reports the estimate of asset allocation of the first step. Although the coefficient of the black group in stock has negatively statistical significance, the other results are similar to Table 4. These results again imply that differences in race and ethnicity influ- ence whether to own assets. Table 8 shows the estimation results of asset allocation of the second step. These results again suggest that white, black, and Hispanic households hold similar asset allocation and that differences by race and ethnicity do not necessarily influence asset allocation.

Table 7. Estimation results of asset allocation: first step

\begin{tabular}{llll}
\hline & Method C & Method C & Method C \\
\hline Race/Ethnicity : ref = white & Stock & Business Equity & Real Estate \\
Black & & & \\
& $-0.256^{*}$ & $-0.334^{* * *}$ & 0.062 \\
Hispanic & $(-1.80)$ & $(-2.60)$ & $(0.49)$ \\
& $-0.486^{* * *}$ & $-0.300^{* *}$ & -0.108 \\
\hline \multirow{2}{*}{ Race/Ethnicity : ref $=$ white } & $(-3.41)$ & $(-2.48)$ & $(-0.95)$ \\
Black & Mutual Fund & US Bond & Transaction Account \\
& & & \\
Hispanic & $-0.765^{* * *}$ & -0.155 & $-0.603^{* * *}$ \\
& $(-2.73)$ & $(-1.20)$ & $(-4.85)$ \\
$\mathrm{N}$ & $-0.480^{* *}$ & $-0.645^{* * *}$ & $-0.300^{* * *}$ \\
\hline
\end{tabular}

Note. $\mathrm{t}$ statistics in parentheses.

${ }^{*} \mathrm{p}<0.1,{ }^{* *} \mathrm{p}<0.05,{ }^{* * *} \mathrm{p}<0.01$.

Table 8. Estimation results of asset allocation: second step

\begin{tabular}{llll}
\hline & Method C & Method C & Method C \\
\hline Race/Ethnicity : ref = white & Stock & Business Equity & Real Estate \\
Black & & & \\
& -0.026 & 0.021 & 0.087 \\
Hispanic & $(-0.34)$ & $(0.25)$ & $(1.25)$ \\
& -0.060 & 0.031 & 0.073 \\
& $(-0.56)$ & $(0.49)$ & $(1.19)$ \\
\hline Race/Ethnicity : ref $=$ white & Mutual Fund & US Bond & Transaction Account \\
Black & & & \\
& 0.009 & -0.007 & 0.045 \\
Hispanic & $(0.04)$ & $(-0.06)$ & $(1.59)$ \\
& -0.024 & -0.102 & $0.081^{* * *}$ \\
$\mathrm{~N}$ & $(-0.18)$ & $(-0.41)$ & $(3.71)$ \\
\hline
\end{tabular}

Note. $\mathrm{t}$ statistics in parentheses.

${ }^{*} \mathrm{p}<0.1,{ }^{* *} \mathrm{p}<0.05,{ }^{* * *} \mathrm{p}<0.01$.

\section{Conclusion}

This study investigates differences in risk tolerance and asset allocation among white, black, and Hispanic households in the United States. This study uses a novel method that combines regression with matching because there are substantial differences in the distributions of covariates among the white, black, and Hispanic groups.

Overall, the estimation results with PSM are different from those of prior studies. First, PSM shows that white, black, and Hispanic respondents are more likely to a similar level of risk whereas prior studies show that 
nonwhite respondents are less likely to take risks than are white respondents. Second, although PSM indicates that black and Hispanic households are less likely to own almost all assets than white households, it also indicates that black households are more likely to own some assets, such as US bonds and real estate, at a similar level to white households. Prior studies may not be able to control differences in covariates reliably in order to regress using the whole sample.

Table 6. Estimation results of risk torelance

\begin{tabular}{ll}
\hline & Method C \\
\hline Race/Ethnicity: ref = white & \\
Black & 0.012 \\
& $(0.08)$ \\
Hispanic & -0.122 \\
& $(-0.93)$ \\
$\mathrm{N}$ & 1,928 \\
\hline
\end{tabular}

Note. $\mathrm{t}$ statistics in parentheses.

${ }^{*} \mathrm{p}<0.1,{ }^{* *} \mathrm{p}<0.05,{ }^{* * *} \mathrm{p}<0.01$.

This study analyze six assets with various risk in order to investigate whether a particular asset is more (or less) likely to be held by a particular race or ethnicity. This study finds that a particular race or ethnicity is less likely to own a particular asset. Black households are much less likely to own transaction accounts and Hispanic households are much less likely to own US bonds. These findings suggest that differences in race and ethnicity affect whether to own assets.

However, as for asset allocation, the results with PSM show that white and black households have similar levels of asset allocation, while, white and Hispanic households have similar levels of asset allocation except for transaction accounts. Hispanic households have higher asset allocation share in transaction accounts than white households. At the same time, the results indicate that Hispanic and black households have the same level of asset allocation. These results suggest that white, black, and Hispanic households have similar asset allocation and that differences by race and ethnicity do not necessarily influence asset allocation.

In practice, there is wealth inequality between white and nonwhite households. Prior studies suggest that the reason wealth inequality arises between white and nonwhite households is that nonwhite households are less likely than white households to take risks and hold risky assets. However, white, black, and Hispanic households are more likely to take risks at a similar level and hold similar asset allocation. Differences by race and ethnicity do not necessarily influence risk tolerance and asset allocation. Therefore, this suggests that wealth inequality between white and nonwhite households is not attributed to asset allocation. It is not necessary to formulate policies that emphasize differences in asset allocation in order to solve wealth inequality between white and nonwhite groups.

With regard to the limitations of this study, unfortunately, the SCF does not provide information on how long respondents have lived in the United States. This information may be useful though Hispanic people have been resilient to acculturation into US culture and preserved their culture (Valencia, 1989). Moreover, the SCF does not provide information about regions. Regional characteristics, such as industrial structure and metropolitan features, may be useful information. Data fusion may help these limitations.

As well as addressing these limitations, future research will investigate whether differences by race or ethnicity affect asset prices under an assumption of downward- sloping demand for assets, provided data are available. White investment activities may affect asset prices substantially as the white population comprised 72 percent of the total population in the 2010 census (Hixson et al., 2011). However, the white population will fall to 47 percent by 2050 since it is increasing more slowly than the nonwhite population (Passel \& Cohn, 2008). Therefore, white investment activities will have a declining effect on asset prices in the future. By contrast, the Hispanic population will increase 43 percent from 2000 to 2010 (Ennis et al., 2011), and so, Hispanic investment activities will affect asset prices in the future.

\section{Acknowlegements}

I am grateful to Shinsuke Ikeda, Wataru Ohta, Yoshiro Tsutsui, and the Kansai Research Group for Econometrics, the Tokyo Center for Economic Research Junior Workshop, Kyoto University Workshop, and the participants of the Japan Economic Association Annual Conference for their helpful remarks. Any mistakes in this article are my own. 


\section{References}

Abadie, A., \& Imbens, G. W. (2011). Bias-Corrected Matching Estimators for Average Treatment Effects. Journal of Business \& Economic Statistics, 29(1), 1-11. https://doi.org/10.1198/jbes.2009.07333

Altonji, J. G., \& Doraszelski, U. (2005). The Role of Permanent Income and Demographics in Black/White Differences in Wealth. Journal of Human Resources, 40(1), 1-30. https://doi.org/10.3368/jhr.XL.1.1

Arrow, K. J. (1971). Essays in the Theory of Risk-Bearing. Markham: Chicago.

Badu, Y. A., Daniels, K. N., \& Salandro, D. P. (1999). An Empirical Analysis of Differences in Black and White Asset and Liability Combinations. Financial Services Review, 8(3), 129-147. https://doi.org/10.1016/S1057-0810(99)00039-6

Barsky, R., Bound, J., Charles, K. K., \& Lupton, J. P. (2002). Accounting for the Black-White Wealth Gap: A Nonparametric Approach. Journal of the American Statistical Associtation, 97(459), 663-673. https://doi.org/10.1198/016214502388618401

Cagetti, M., \& De Nardi, M. (2008). Wealth Inequality: Data and Models. Macroecnomic Dynamics, 12, $285-313$. https://doi.org/10.1017/S1365100507070150

Campbell, J. Y. (2006). Household Finance. The Journal of Finance, 61(4), 1553-1604. https://doi.org/10.1111/j.1540-6261.2006.00883.X

Casas, J. M., Wagenheim, B. R., Banchero, R., \& Mendoza-Romero, J. (1994). Hispanic Masculin- ity: Myth or Psychological Schema Meriting Clinical Consideration. Hispanic Journal of Behavioral Sciences, 16(3), 315-331. https://doi.org/10.1177/07399863940163009

Choudhury, S. (2001). Racial and Ethnic Differences in Wealth and Asset Choices. Social Security Bulletin, 64(4), $1-15$.

Cochran, W. G. (1965). The Planning of Observational Studies of Human Populations. Journal of the Royal Statistical Society. Series A, 128(2), 234-266. https://doi.org/10.2307/2344179

Coleman, S. (2003). Risk Tolerance and the Investment Behavior of Black and Hispanic Heads of Household. Journal of Financial Counseling and Planning, 14(2), 43-52.

Dehejia, R. H., \& Wahba, S. (1999). Causal Effects in Nonexperimental Studies: Reevaluating the Evaluation of Training Programs. Journal of the American Statistical Association, 94(448), 1053-1062. https://doi.org/10.1080/01621459.1999.10473858

Dehejia, R. H., \& Wahba, S. (2002). Propensity Score-Matching Methods for Nonexperimental Causal Studies. The Review of Economics and Statistics, 84(1), 151-161. https://doi.org/10.1162/003465302317331982

Ennis, S. R., R'1os-Vargas, M., \& Albert, N. G. (2011). The Hispanic Population: 2010. US Department of Commerce, Economics and Statistics Administration, US Census Bureau.

Glazerman, S., Levy, D. M., \& Myers, D. (2003). Nonexperimental versus Experimental Estimates of Earnings Impacts. Annals of the American Academy of Political and Social Science, 589(1), 63-93. https://doi.org/10.1177/0002716203254879

Gutter, M. S., \& Fontes, A. (2006). Racial Differences in Risky Asset Ownership: A Two-Stage Model of the Investment Decision-Making Process. Journal of Financial Counseling and Planning, 17(2), 64-78.

Gutter, M. S., Fox, J. J., \& Montalto, C. P. (1999). Racial Differences in Investor Decision Making. Financial Services Review, 8(3), 149-162. https://doi.org/10.1016/S1057-0810(99)00040-2

Haliassos, M., \& Bertaut, C. C. (1995). Why Do So Few Hold Stocks? The Economic Journal, 105(432), 1110-1129. https://doi.org/10.2307/2235407

Hanna, S. D., Wang, C., \& Yuh, Y. (2010). Racial/Ethnic Differences in High Return Investment Ownership: A Decomposition Analysis. Journal of Financial Counseling and Planning, 21(2), 44-59.

Heckman, J. J. (1979). Sample Selection Bias as a Specification Error. Econometrica, 47(1), $153-161$. https://doi.org/10.2307/1912352

Hill, J., \& Reiter, J. P. (2006). Interval Estimation for Treatment Effects Using Propensity Score Matching. Statistics in Medicine, 25(13), 2230-2256. https://doi.org/10.1002/sim.2277

Hixson, L., Hepler, B. B., \& Kim, M. O. (2011). The White Population: 2010. US Department of Commerce, Economics and Statistics Administration, US Census Bureau. 
Kara, A., \& Kara, N. R. (1996). Ethnicity and Consumer Choice: A Study of Hispanic Decision Processes across Different Acculturation Levels. Journal of Applied Business Research, 12(2), 22-34. https://doi.org/10.19030/jabr.v12i2.5823

Keister, L. A. (2000). Race and Wealth Inequality: The Impact of Racial Differences in Asset Ownership on the Distribution of Household Wealth. Social Science Research, 29(4), 477-502. https://doi.org/10.1006/ssre.2000.0677

Kennickell, A. B., McManus, D. A., \& Woodburn, R. L. (1996). Weighting Design for the 1992 Survey of Consumer Finances. Working Paper, Board of Governors of the Federal Reserve System.

Montalto, C. P., \& Sung, J. (1996). Multiple Imputation in the 1992 Survey of Consumer Finances. Journal of Financial Counseling and Planning, 7, 133-146.

Ogden, D. T., Ogden, J. R., \& Schau, H. J. (2004). Exploring the Impact of Culture and Acculturation on Consumer Purchase Decisions: Toward a Microcultural Perspective. Academy of Marketing Science Review, $8(3), 1-22$.

Okun, B. F., Fried, J., \& Okun, M. L. (1998). Understanding Diversity: A Learning-As-Practice Primer. Wadsworth: Belmont, CA.

Passel, J. S., \& Cohn, D. (2008). U.S. Population Projections: 2005-2050. Pew Research Center: Washington, DC.

Rokeach, M., \& Parker, S. (1970). Values as Social Indicators of Poverty and Race Relations in America. The ANNALS of the American Academy of Political and Social Science, 388(1), 97-111. https://doi.org/10.1177/000271627038800110

Rosenbaum, P. R., \& Rubin, D. B. (1983). The Central Role of the Propensity Score in Observa- tional Studies for Causal Effects. Biometrika, 70(1), 41-55. https://doi.org/10.1093/biomet/70.1.41

Rosenbaum, P. R., \& Rubin, D. B. (1985). Constructing a Control Group Using Multivariate Matched Sampling Methods that Incorporate the Propensity Score. The American Statistician, 39(1), 33-38.

Rubin, D. B. (1973). The Use of Matched Sampling and Regression Adjustment to Remove Bias in Observational Studies. Biometrics, 29(1), 185-203. https://doi.org/10.2307/2529685

Rubin, D. B. (1979). Using Multivariate Matched Sampling and Regression Adjustment to Control Bias in Observational Studies. Journal of the American Statistical Association, 74(366), 318-328. https://doi.org/10.2307/2286330

Rubin, D. B. (1987). Multiple Imputation for Nonresponse in Surveys. New York: John Wiley \& Sons. https://doi.org/10.1002/9780470316696

Rubin, D. B. (2001). Using Propensity Scores to Help Design Observational Studies: Application to the Tobacco Litigation. Health Services and Outcomes Research Methodology, 2(3), 169-188. https://doi.org/10.1023/A:1020363010465

Rubin, D. B., \& Thomas, N. (2000). Combining Propensity Score Matching with Additional Adjustments for Prognostic Covariates. Journal of the American Statistical Association, 95(450), 573-585. https://doi.org/10.1080/01621459.2000.10474233

Smith, J. A., \& Todd, P. E. (2005). Does matching overcome LaLonde's critique of nonexperimental estimators? Journal of Econometrics, 125(1-2), 305-353. https://doi.org/10.1016/j.jeconom.2004.04.011

Straight, R. L. (2002). Wealth: Asset-Accumulation Differences by Race: SCF Data, 1995 and 1998. The American Economic Review, 92(2), 330-334. https://doi.org/10.1257/000282802320191552

Sung, J., \& Hanna, S. (1996). Factors Related To Risk Tolerance. Journal of Financial Coun- seling and Planning, 7, 11-19.

Terrell, H. S. (1971). Wealth Accumulation of Black and White Families: The Empirical Evidence. The Journal of Finance, 26(2), 363-377. https://doi.org/10.2307/2326053

Valencia, H. (1989). Hispanic Values and Subcultural Research. Journal of the Academy of Marketing Science, 17(1), 23-28. https://doi.org/10.1007/BF02726350

Wang, H., \& Hanna, S. D. (1997). Does Risk Tolerance Decrease with Age? Journal of Financial Counseling and Planning, 8(2), 27-32.

Yao, R., Gutter, M. S., \& Hanna, S. D. (2005). The Financial Risk Tolerance of Blacks, Hispanics and Whites. 
Journal of Financial Counseling and Planning, 16(1), 51-62.

Yao, R., Sharpe, D. L., \& Wang, F. (2011). Decomposing the Age Fffect on Risk Tolerance. The Journal of Socio-Economics, 40(6), 879-887. https://doi.org/10.1016/j.socec.2011.08.023

Yinger, J. M. (1985). Ethnicity. Annual Review of Sociology, 11, 151-180. https://doi.org/10.1146/annurev.so.11.080185.001055

Zhong, L. X., \& Xiao, J. J. (1995). Determinants of Family Bond and Stock Holdings. Journal of Financial Counseling and Planning, 6, 1-8.

\section{Notes}

Note 1. Note that here, descriptive statistics are unweighted. Like prior studies, regression analyses are not considered on weights because Montalto and Sung (1996) indicate that weighted regression will not correct the standard errors for the complex sampling design in the SCF. The weighted descriptive statistics in Table A1 of Appendix may not be consistent whit the descriptive statistics in Table 1.

Note 2. The common support is to overlap the distribution of propensity score in the groups.

Note 3 . The propensity score is estimated by a logit model with variables of gender, age, years of schooling, marital status, family size, number of children, employment status, risk tolerance, expectations of US economy over the next 5 years, health status, log usual income, and log net worth. A constant value is added to income and net worth before taking logs to avoid the issue with non-positive values.

Note 4. This study changes the order of risk tolerance in the SCF to facilitate the interpretation, that is, there is

a change from 1 to 4 in "take substantial financial risks expecting to earn substantial returns," a change from 2 to 3 in "take above average financial risks expecting to earn above average returns," a change from 3 to 2 in "take average financial risks expecting to earn average returns," and a change from 4 to 1 in "not willing to take any financial risks." In addition, a constant value is added to income and net worth before taking logs to avoid the issue with non-positive values.

Note 5. Like Campbell (2006), this study controls log income, squared log income, log net worth, and squared $\log$ net worth. A constant value is added to income and net worth before taking logs to avoid the issue with non-positive values.

\section{Appendix}

\section{Descriptive Statistics}

Table A1 shows the descriptive statistics of weighted characteristics. As described in footnote 1, the descriptive statistics in Table A.1 may not be consistent with the unweighted descriptive statistics in Table 1. For example, in Table A1, average family size of white households is 2.346 , while, in Table 1, average family size of white households is 2.463. In addition, Table A2 shows the descriptive statistics of weighted assets. The proportion of households owning stocks is 18.3 percent for whites, 6.2 percent for blacks, and 3.1 percent for Hispanics. As indicated in Haliasson and Bertaut (1995), the proportion of stocks owned is not large.

Table A1. Descriptive statistics of weighted characteristics

\begin{tabular}{lllll}
\hline & White Mean & Black Mean & Hispanic Mean & All \\
\hline Male & 0.756 & $0.567^{* * *}$ & $0.733^{* *, 3}$ & 0.726 \\
Age & 52.383 & $48.098^{* * *}$ & $42.433^{* * *, 3}$ & 50.639 \\
Years of schooling & 13.731 & $12.977^{* * *}$ & $11.494^{* * * * 3}$ & 13.369 \\
Married & 0.624 & $0.450^{* * *}$ & $0.667^{* * *, 3}$ & 0.604 \\
Family size & 2.346 & 2.316 & $3.095^{* * *, 3}$ & 2.426 \\
The number of children & 1.419 & $1.579^{* * *}$ & $1.226^{* * *, 3}$ & 1.420 \\
The proportion of children & 0.560 & 0.573 & $0.476^{* * *, 3}$ & 0.552 \\
Not working & 0.330 & $0.361^{* *}$ & $0.182^{* * *, 3}$ & 0.318 \\
Risk tolerance & & & & \\
No financial risks & 0.433 & $0.568^{* * *}$ & $0.650^{* * * * 3}$ & 0.477 \\
Average financial risks & 0.389 & $0.294^{* * *}$ & $0.229^{* * *, 3}$ & 0.357 \\
\hline
\end{tabular}




\begin{tabular}{lllll}
\hline Above average financial risks & 0.145 & $0.098^{* * *}$ & $0.080^{* * *, 1}$ & 0.131 \\
Substantial financial risks & 0.032 & 0.039 & $0.042^{* *}$ & 0.034 \\
US economy over the next 5 years & & & & 0.186 \\
Worse & 0.211 & $0.094 * * *$ & $0.142^{* * *, 3}$ & 0.289 \\
About the same & 0.304 & $0.220 * * *$ & $0.278^{*, 3}$ & 0.525 \\
Better & 0.485 & $0.686 * * *$ & $0.580^{* * *, 3}$ & \\
Health status & & & & 0.063 \\
Poor & 0.062 & 0.070 & 0.059 & 0.199 \\
Fair & 0.186 & $0.261^{* * *}$ & 0.1983 & 0.480 \\
Good & 0.486 & $0.440^{* * *}$ & 0.4932 & 0.259 \\
Excellent & 0.266 & $0.229^{* * *}$ & 0.250 & 75,146 \\
Current income(\$) & 85,732 & $41,302^{* * *}$ & $48,986^{* * *, 2}$ & 10.632 \\
Log current income & 10.739 & $10.273^{* * *}$ & $10.386^{* * * 3}$ & 80,297 \\
Usual income(\$) & 91,041 & $45,399^{* * *}$ & $54,447^{* * *, 2}$ & 10.789 \\
Log usual income & 10.901 & $10.407^{* * *}$ & $10.546^{* * * 3}$ & 529,308 \\
Net worth $\$$ ) & 674,876 & $105,019^{* * *}$ & $116,679^{* * *}$ & 15.873 \\
Log net worth & 15.887 & $15.834^{* * *}$ & $15.834^{* * *}$ & 6,188 \\
$\mathrm{~N}$ & 4,759 & 790 & 639 & \\
\hline
\end{tabular}

Note. Multiple imputation, sampling, and replication weights are used.

${ }^{*} \mathrm{p}<0.1,{ }^{* *} \mathrm{p}<0.05,{ }^{* * *} \mathrm{p}<0.01$ when compared with white.

${ }^{1} \mathrm{p}<0.1,{ }^{2} \mathrm{p}<0.05,{ }^{3} \mathrm{p}<0.01$ when compared with black.

Table A2. Descriptive statistics of weighted assets

\begin{tabular}{lllll}
\hline & White Mean & Black Mean & Hispanic Mean & All \\
\hline Stock & 40,425 & $3,723^{* * *}$ & $1,742^{* * *}$ & 30,741 \\
Proportion & 0.183 & $0.062^{* * *}$ & $0.031^{* * *, 3}$ & 0.148 \\
Business equity & 125,724 & $4,946^{* * *}$ & $19,537^{* * *, 2}$ & 96,239 \\
Proportion & 0.157 & $0.056^{* * *}$ & $0.060^{* * *}$ & 0.131 \\
Real estate & 123,666 & $28,140^{* * *}$ & $20,407^{* * *}$ & 98,172 \\
Proportion & 0.216 & $0.134^{* * *}$ & $0.085^{* * *}, 3$ & 0.189 \\
Mutual funds & 44,520 & $1,038^{* * *}$ & $3,321^{* * *}$ & 33,569 \\
Proportion & 0.112 & $0.014^{* * *}$ & $0.015^{* * *}$ & 0.087 \\
US government savings bonds & 860 & 752 & $62^{* * * 3}$ & 755 \\
Proportion & 0.146 & $0.081^{* * *}$ & $0.026^{* * * 3}$ & 0.123 \\
Transaction accounts & 37,439 & $5,307^{* * *}$ & $6,107^{* * *}$ & 29,247 \\
Proportion & 0.962 & $0.809^{* * *}$ & $0.832^{* * *}$ & 0.925 \\
$\mathrm{~N}$ & 4,759 & 790 & 639 & 6,188 \\
\hline
\end{tabular}

Note. Multiple imputation, sampling, and replication weights are used; the unit is $\$ 1$.

${ }^{*} \mathrm{p}<0.1,{ }^{* *} \mathrm{p}<0.05,{ }^{* * *} \mathrm{p}<0.01$ when compared with white.

${ }^{1} \mathrm{p}<0.1,{ }^{2} \mathrm{p}<0.05,{ }^{3} \mathrm{p}<0.01$ when compared with black.

\section{Copyrights}

Copyright for this article is retained by the author(s), with first publication rights granted to the journal.

This is an open-access article distributed under the terms and conditions of the Creative Commons Attribution license (http://creativecommons.org/licenses/by/4.0/). 